\title{
Characterization of Cellular Defects of Insulin Action in Type 2 (Non-insulin-dependent) Diabetes Mellitus
}

Stefano Del Prato, Riccardo C. Bonadonna, Enzo Bonora, Giovanni Gulli, Anna Solini, Myron Shank, and Ralph A. DeFronzo Division of Diabetes, University of Texas Health Science Center and Audie L. Murphy Veterans Administration Hospital, San Antonio, Texas 78284; and Cattedra di Malattie del Ricambio, University of Padua, I-35128 Padua, Italy

\section{Abstract}

Seven non-insulin-dependent diabetes mellitus (NIDDM) patients participated in three clamp studies performed with [3$\left.{ }^{3} \mathrm{H}\right]$ - and [ $\left.\mathrm{U}-^{14} \mathrm{C}\right]$ glucose and indirect calorimetry: study $\mathrm{I}$, euglycemic ( $5.2 \pm 0.1 \mathrm{mM})$ insulin ( $269 \pm 39 \mathrm{pM}$ ) clamp; study II, hyperglycemic (14.9 $\pm 1.2 \mathrm{mM})$ insulin $(259 \pm 19 \mathrm{pM})$ clamp; study III, euglycemic $(5.5 \pm 0.3 \mathrm{mM})$ hyperinsulinemic $(1650 \pm 529 \mathrm{pM})$ clamp. Seven control subjects received a euglycemic $(5.1 \pm 0.2 \mathrm{mM})$ insulin $(258 \pm 24 \mathrm{pM})$ clamp. Glycolysis and glucose oxidation were quantitated from the rate of appearance of ${ }^{3} \mathrm{H}_{2} \mathrm{O}$ and ${ }^{14} \mathrm{CO}_{2}$; glycogen synthesis was calculated as the difference between body glucose disposal and glycolysis. In study I, glucose uptake was decreased by $54 \%$ in NIDDM vs. controls. Glycolysis, glycogen synthesis, and glucose oxidation were reduced in NIDDM patients $(P<0.05-0.001)$. Nonoxidative glycolysis and lipid oxidation were higher. In studies II and III, glucose uptake in NIDDM was equal to controls $(40.7 \pm 2.1$ and $40.7 \pm 1.7 \mu \mathrm{mol} / \mathrm{min} \cdot \mathrm{kg}$ fat-free mass, respectively). In study II, glycolysis, but not glucose oxidation, was normal $(P<0.01$ vs. controls $)$. Nonoxidative glycolysis remained higher $(P<0.05)$. Glycogen deposition increased $(P$ $<0.05$ vs. study $I$ ), and lipid oxidation remained higher ( $P$ $<0.01$ ). In study III, hyperinsulinemia normalized glycogen formation, glycolysis, and lipid oxidation but did not normalize the elevated nonoxidative glycolysis or the decreased glucose oxidation. Lipid oxidation and glycolysis $(r=-0.65 ; P$ $<0.01)$, and glucose oxidation $(r=-0.75 ; P<0.01)$ were inversely correlated. In conclusion, in NIDDM: $(a)$ insulin resistance involves glycolysis, glycogen synthesis, and glucose oxidation; ( b ) hyperglycemia and hyperinsulinemia can normalize total body glucose uptake; (c) marked hyperinsulinemia normalizes glycogen synthesis and total flux through glycolysis, but does not restore a normal distribution between oxidation and nonoxidative glycolysis; $(d)$ hyperglycemia cannot overcome the defects in glucose oxidation and nonoxidative glycolysis; (e) lipid oxidation is elevated and is suppressed only with hyperinsulinemia. (J. Clin. Invest. 1993. 91:484-494.) Key words: glycolysis • glucose oxidation • glycogen synthesis • hyperglycemia $\bullet$ hyperinsulinemia

Address reprint requests to Dr. Stefano Del Prato, Cattedra di Malattie del Ricambio, Via Giustiniani 2, I-35128 Padova, Italy; or to Dr. Ralph A. DeFronzo, Diabetes Division, The University of Texas Health Science Center, 7703 Floyd Curl Drive, San Antonio, TX 78284-7886.

Received for publication 22 November 1991 and in revised form 18 September 1992.

J. Clin. Invest.

(c) The American Society for Clinical Investigation, Inc.

$0021-9738 / 93 / 02 / 0484 / 11 \$ 2.00$

Volume 91, February 1993, 484-494

\section{Introduction}

Insulin resistance represents a clinical condition in which the ability of insulin to normally promote glucose metabolism is impaired. In type 2 (non-insulin-dependent) diabetes mellitus (NIDDM), ${ }^{1}$ numerous studies have demonstrated the presence of insulin resistance (1-4). Nonetheless, the cellular defect(s) responsible for the alteration in insulin action has (have) yet to be identified. Insulin-mediated glucose utilization occurs via the sequential and coordinated activation of several membrane and intracellular steps, including insulin binding to a specific membrane receptor, generation of a second messenger for insulin action, stimulation of glucose transport and glucose phosphorylation, and enzymatic regulation of intracellular glucose metabolism. Most evidence does not support a defect in insulin receptor number or affinity $(5,6)$; in contrast, many studies have documented a variety of postbinding defects in insulin action $(3,4,7,8)$. In an attempt to evaluate the integrity of the intracellular pathways of glucose metabolism in NIDDM, investigators have employed indirect calorimetry in combination with the glucose clamp technique (9). Glucose oxidation, as measured by indirect calorimetry, has been shown to be reduced in NIDDM patients $(10,11)$. The difference between the rate of total body glucose disposal and glucose oxidation under insulin-stimulated conditions represents nonoxidative glucose metabolism, which has been shown to correlate closely with the rate of glycogen formation in the whole body $(12,13)$. In NIDDM, nonoxidative glucose metabolism is markedly reduced compared to normal individuals $(11,14)$. However, it should be recognized that these measurements represent an oversimplification of the multiple intracellular pathways involved in intracellular glucose metabolism and their specific enzymatic control. Specifically, indirect calorimetry measures the net balance of three different metabolic fluxes that occur simultaneously at the whole-body level: glucose oxidation (positive), glucose conversion to lipids (positive), and amino acid conversion to glucose (negative). Moreover, nonoxidative glucose disposal represents the sum of glycogen formation and anaerobic glycolysis and these cannot be distinguished by employing indirect calorimetry in combination with the isotopic measurement of whole-body glucose disposal. To provide a more precise characterization of the intracellular steps involved in glucose utilization, we have employed a double-tracer technique that enables us to dissect out the specific contributions of total glycolysis, nonoxidative glycolysis, glucose oxidation, and glycogen synthesis to the insulin

1. Abbreviations used in this paper: CV, coefficient of variation; FFA, free fatty acids; FFM, fat-free mass; HGP, hepatic glucose production; NIDDM, non-insulin-dependent diabetes mellitus; $\mathrm{PDH}$, pyruvate dehydrogenase. 
resistance observed in NIDDM. Although presently available data suggest the presence of an impairment in intracellular glucose metabolism, the possibility that reduced oxidative and nonoxidative glucose metabolism simply may be secondary to a reduced rate of glucose transport into a cell remains to be elucidated. Both hyperglycemia and hyperinsulinemia can increase glucose utilization and normalize total body glucose flux in NIDDM subjects $(15,16)$. It has been suggested that elevation in the plasma concentrations of glucose and insulin may play a compensatory role in maintaining adequate glucose uptake in the presence of insulin resistance $(15,16)$. More recently, Baron and his co-workers have extensively analyzed the metabolic effect of various combinations of plasma insulin and glucose concentrations on whole-body glucose disposal (17, 18). Nevertheless, it remains unknown whether the normalization of glucose uptake by hyperglycemia and / or hyperinsulinemia can correct the defects in intracellular glucose metabolism in NIDDM. If so, it can be argued that the defect in insulin action resides at a step prior to the activation of the key intracellular enzymes involved in glucose metabolism. In the present study, we have investigated some of the intracellular pathways involved in glucose metabolism before and after the rate of whole-body glucose metabolism in NIDDM patients was matched with controls either by elevating the plasma glucose or insulin concentrations.

\section{Methods}

\section{Subjects}

Seven patients with onset of NIDDM after the age of $40 \mathrm{yr}$ and seven control subjects participated in the present study. Control subjects had a normal oral glucose tolerance test and no family history of NIDDM. The clinical and laboratory characteristics of the study population are given in Table $I$. The duration of diabetes was $10 \pm 3$ yr. Fasting plasma glucose was $10.1 \pm 1.3 \mathrm{mM}$ (mean $\pm \mathrm{SEM}$ ), indicating moderately poor glycemic control. Five patients were treated with sulfonylureas and two with diet alone. Sulfonylurea treatment was stopped $3 \mathrm{~d}$ before each study; in no subject was this associated with a change in fasting plasma glucose concentration. None of the diabetic or control subjects had any clinical or laboratory evidence of hepatic, renal, or other endocrine disease. No subjects were taking any medication. The purpose, nature, and potential risks of the study were explained to all subjects, and

Table I. Clinical and Laboratory Characteristics of the Study Population in the Postabsorptive State

\begin{tabular}{lcc}
\hline & $\begin{array}{c}\text { Control } \\
\text { subjects }\end{array}$ & $\begin{array}{c}\text { NIDDM } \\
\text { patients }\end{array}$ \\
\hline Number & 7 & 7 \\
Sex $(\mathrm{M} / \mathrm{F})$ & $3 / 4$ & $5 / 2$ \\
Age $(\mathrm{yr})$ & $47 \pm 3$ & $56 \pm 3$ \\
Body weight $(\mathrm{kg})$ & $60 \pm 3$ & $72 \pm 1^{\ddagger}$ \\
Height $(\mathrm{cm})$ & $1.56 \pm 0.02$ & $1.69 \pm 0.03^{\ddagger}$ \\
Body mass index $\left(\mathrm{kg} / \mathrm{m}^{2}\right)$ & $24.5 \pm 0.6$ & $25.4 \pm 0.7$ \\
FFM (\%) & $68.5 \pm 2.6$ & $72.1 \pm 2.3$ \\
Fat mass $(\%)$ & $31.5 \pm 2.6$ & $27.9 \pm 2.3$ \\
Plasma glucose $(m M)$ & $4.8 \pm 0.2$ & $10.1 \pm 1.3^{\ddagger}$ \\
Plasma insulin $(p M)$ & $48 \pm 5$ & $95 \pm 19^{*}$ \\
Plasma FFA $(m M)$ & $0.62 \pm 0.07$ & $0.83 \pm 0.06^{*}$ \\
Plasma lactate $(m M)$ & $0.79 \pm 0.07$ & $1.31 \pm 0.12^{\ddagger}$ \\
\end{tabular}

${ }^{*} P<0.05 ;{ }^{\ddagger} P<0.01$ vs. control subjects. written consent was obtained from each individual before their participation. The protocol was reviewed and approved by the Institutional Review Board at the University of Texas Health Science Center, and by the Radiation Safety Committee, the General Clinical Research Committee, the Research and Development Committee, and the Radioactive Drug Research Committee at the Audie L. Murphy Veterans Administration Hospital at San Antonio.

\section{Experimental design}

Normal subjects underwent a single euglycemic insulin $(20 \mathrm{mU} /$ $\mathrm{min} \cdot \mathrm{m}^{2}$ ) clamp. Diabetic patients were studied on three different occasions as follows: $(a)$ euglycemic insulin $\left(20 \mathrm{mU} / \mathrm{min} \cdot \mathrm{m}^{2}\right)$ clamp; (b) hyperglycemic insulin $\left(20 \mathrm{mU} / \mathrm{min} \cdot \mathrm{m}^{2}\right)$ clamp; (c) euglycemic hyperinsulinemic clamp (see below for details). All studies lasted $4 \mathrm{~h}$. In studies 2 and 3, plasma glucose and insulin concentrations, respectively, were raised sufficiently to achieve a rate of total body glucose disposal similar to that observed in the normal individuals during the euglycemic insulin clamp. All studies were carried out in combination with a primed-continuous infusion of $3-\left[{ }^{3} \mathrm{H}\right]$ - and U- $\left[{ }^{14} \mathrm{C}\right]$ glucose infusion and indirect calorimetry (see below for details). Studies were performed at 8-10-d intervals. On a separate occasion, in all subjects an intravenous bolus of ${ }^{3} \mathrm{H}_{2} \mathrm{O}$ was administered for the calculation of fat-free mass (FFM) (19).

\section{Insulin clamp studies}

All studies were performed at $0800 \mathrm{~h}$ after a $10-12$-h overnight fast. A 20-gauge Teflon catheter was inserted into an antecubital vein for the infusion of all test substances. A second catheter was inserted retrogradely into a wrist vein for blood sampling. The cannula was kept patent with a slow infusion of normal saline $(\mathrm{NaCl} 0.9 \%)$. The hand was then inserted into a heated box $\left(65^{\circ} \mathrm{C}\right)$ to allow arterialization of the venous blood. 40-60 min were allowed for the subjects to get acquainted with the environmental setup. After collection of basal blood samples, an insulin (Humulin R, Eli Lilly \& Co., Indianapolis, IN) infusion was started and maintained for the following $240 \mathrm{~min}$. During the insulin infusion period, the plasma glucose concentration was measured at 5-10-min intervals and a variable infusion of a $20 \%$ glucose solution was periodically adjusted to maintain the plasma glucose concentration at the desired goal (see Table II) as previously described (20). Control subjects participated only in the euglycemic clamp as described above; the NIDDM patients were studied on three different occasions:

Study 1. A 240 -min euglycemic insulin ( $269 \pm 39 \mathrm{pM})$ clamp was performed as described in the control group. After starting the insulin infusion plasma glucose was allowed to drop to a euglycemic level $(5.2 \pm 0.1 \mathrm{mM}$; coefficient of variation $[\mathrm{CV}]=2.8 \pm 0.7 \%)$ that was maintained until completion of the study. In all patients euglycemia was attained within 90-125 min.

Study 2. In this study, the total body glucose utilization rate of NIDDM patients was matched to that observed in control subjects by increasing the plasma glucose concentration (mean $14.9 \pm 1.2 \mathrm{mM}$ ). At the start of the insulin infusion a glucose infusion was begun at a rate similar to that in control subjects during the last hour of the euglycemic insulin $(259 \pm 19 \mathrm{pM})$ clamp. The plasma glucose concentration reached a new plateau after 60-95 min, and remained constant at this level until the end of the study $(\mathrm{CV}=2.8 \pm 0.6 \%)$.

Study 3. In this study, the total body glucose disposal rate of NIDDM was matched to that observed in control subjects by raising the plasma insulin level. After beginning the insulin infusion, the plasma glucose concentration was allowed to drop until euglycemia $(5.5 \pm 0.3 \mathrm{mM} ; \mathrm{CV}=4.5 \pm 0.7 \%)$ was attained. Euglycemia was then maintained by means of a glucose infusion rate similar to that in control subjects during the last hour of the euglycemic hyperinsulinemic $(1,650 \pm 529 \mathrm{pM})$ clamp and by fine adjustment of the insulin infusion rate (20). Both insulin and glucose infusions remained constant during the last $120 \mathrm{~min}$ of the study. The steady-state plasma glucose and insulin concentrations during each clamp protocol are displayed in Table II. 
Table II. Plasma Insulin and Substrate Concentrations in Control Subjects and NIDDM Patients during the Last Hour of the Clamp Studies

\begin{tabular}{|c|c|c|c|c|}
\hline & $\begin{array}{l}\text { Plasma } \\
\text { glucose }\end{array}$ & $\begin{array}{l}\text { Plasma } \\
\text { insulin }\end{array}$ & $\begin{array}{l}\text { Plasma } \\
\text { lactate }\end{array}$ & $\begin{array}{c}\text { Plasma } \\
\text { FFA }\end{array}$ \\
\hline & $m M$ & $p M$ & $m M$ & $m M$ \\
\hline I. Controls ( $20 \mathrm{mU}$ insulin clamp) & $5.1 \pm 0.2$ & $258 \pm 24$ & $0.78 \pm 0.08$ & $0.11 \pm 0.01$ \\
\hline II. NIDDM ( $20 \mathrm{mU}$ insulin clamp) & $5.2 \pm 0.1$ & $269 \pm 39$ & $1.29 \pm 0.07^{*}$ & $0.31 \pm 0.09 *$ \\
\hline III. NIDDM (hyperglycemic clamp) & $14.9 \pm 1.2^{\S}$ & $259 \pm 19$ & $1.07 \pm 0.06^{\ddagger}$ & $0.16 \pm 0.03$ \\
\hline IV. NIDDM (hyperinsulinemic clamp) & $5.5 \pm 0.3$ & $1650 \pm 529^{\ddagger}$ & $0.95 \pm 0.06^{*}$ & $0.19 \pm 0.04^{\ddagger}$ \\
\hline
\end{tabular}

${ }^{*} P<0.02 ;{ }^{\ddagger} P<0.01 ;{ }^{\S} P<0.001$ vs. control subjects.

\section{Tracer infusions}

To minimize the amount of radioactivity to be administered, no tracer was used during the basal state. After $120 \mathrm{~min}$ of each insulin/glucose clamp, a near steady-state condition for total body glucose metabolic rate was approached. At this time a prime-continuous infusion of 3$\left[{ }^{3} \mathrm{H}\right]-$ and $\mathrm{U}-\left[{ }^{14} \mathrm{C}\right]$ glucose was started $(0.4$ and $0.2 \mu \mathrm{Ci} / \mathrm{min}$, respectively). The ratio of the prime to the constant infusion was calculated for each subject according to the following formula:

Prime/constant infusion

$=[$ plasma glucose concentration $] \times[0.25] /[$ glucose infusion rate $]$,

where 0.25 is the fractional total distribution volume of glucose in the body ( 21 ), the plasma glucose concentration is in $\mathrm{mM}$, and the glucose infusion in $\mu \mathrm{mol} / \mathrm{kg} \cdot \mathrm{min}$. In all subjects, in all studies, a steady-state plasma specific activity $\left(\mathrm{CV}=4.8 \pm 0.5\right.$ and $6.5 \pm 0.9 \%$ for $3-\left[{ }^{3} \mathrm{H}\right]-$ and $\mathrm{U}-\left[{ }^{14} \mathrm{C}\right]$ glucose, respectively) was reached during the last hour of the insulin/glucose clamp studies as shown in Fig. 1.

Arterialized blood samples were obtained at 5-10-min intervals during the insulin infusion to monitor the plasma glucose concentration and adjust the exogenous glucose infusion rate according to a negative feedback principle (20). Arterialized blood samples for the determination of plasma glucose specific activity and free fatty acid (FFA), lactate and insulin concentrations were collected at 10-min intervals during the last hour of the clamp study.

\section{Respiratory exchange measurements}

During the last hour of all studies, continuous indirect calorimetry (Deltatrac, Sensormedics, Anaheim, CA) with a canopy system was employed to measure rates of $\mathrm{O}_{2}$ consumption and $\mathrm{CO}_{2}$ production. Protein oxidation was calculated from the rate of non-protein urinary nitrogen excretion measured before and during the clamp studies (21). Net rates of carbohydrate and lipid oxidation were calculated from the non-protein respiratory quotient as previously described (21). Expired air samples were collected at 10-min intervals during the last $60 \mathrm{~min}$ of the insulin/glucose clamp studies and bubbled through a $\mathrm{CO}_{2}$ trapping solution (hyamine hydroxide/absolute ethanol/0.1\% phenolphtalein; 3:5:1 ). The solution was titrated with $1 \mathrm{~N} \mathrm{HCl}$ to trap $1 \mathrm{mM} \mathrm{CO}_{2}$ per 3 ml of solution. $1 \mathrm{ml}$ of the saturated solution was added to $5 \mathrm{ml}$ of scintillation liquid and ${ }^{14} \mathrm{C}$ radioactivity was measured using a $\beta$-scintillation counter (Beckman Instruments, Inc., Fullerton, CA) and expired $\mathrm{CO}_{2}$ specific activity was calculated.

\section{Calculations}

Glucose disposal rate and hepatic glucose production (HGP). Glucose turnover rate was calculated by dividing the tracer infusion rate (dpm/ $\mathrm{min})$ by the steady-state plasma glucose specific activity $(\mathrm{dpm} / \mu \mathrm{mol})$ (22). To calculate the actual rate of cellular glucose uptake by all tissues of the body, the rate of glucose disappearance (calculated from the 3- $\left[{ }^{3} \mathrm{H}\right]$-glucose turnover data) was corrected for any urinary glucose loss and any change in the glucose pool (22). Both of these corrections were $<0.6 \mu \mathrm{mol} / \mathrm{min} \cdot \mathrm{kg}$ FFM in all subjects. Residual HGP during the clamp studies was calculated by subtracting the rate of exogenously infused glucose from the rate of appearance of $3-\left[{ }^{3} \mathrm{H}\right]$ glucose turnover rate.

Plasma glucose oxidation. Oxidation of plasma glucose during $\left[{ }^{14} \mathrm{C}\right]$-glucose infusion was calculated from the specific activity of expired $\mathrm{CO}_{2}$ in air samples obtained at 10 -min intervals during the last 60 min of the clamp studies. Total ${ }^{14} \mathrm{CO}_{2}$ expired per min was determined by multiplying ${ }^{14} \mathrm{CO}_{2}$ specific activity by the total $\mathrm{CO}_{2}$ production rate measured by indirect calorimetry (see above), assuming $81 \%$ recovery of ${ }^{14} \mathrm{CO}_{2}$ from the bicarbonate pool (23). During the last hour of each study a steady-state plateau for ${ }^{14} \mathrm{CO}_{2}$ production occurred (Fig. 1). Under this condition the rate of plasma glucose oxidation can be calculated from the ${ }^{14} \mathrm{CO}_{2}$ production rate $(\mathrm{dpm} / \mathrm{min})$ divided by the steady state plasma $\left[{ }^{14} \mathrm{C}\right]$ glucose specific activity $(\mathrm{dpm} / \mu \mathrm{mol})$.

Glycolytic flux. During the glycolytic process, essentially all of tritium in the C-3 position of the glucose molecule is lost in water at the triose-isomerase step. Generation of $\left[{ }^{3} \mathrm{H}\right]$ glycerol from $3-\left[{ }^{3} \mathrm{H}\right]$ glucose is negligible (22). Although some tritiated water also may be formed during the fructose-6-phosphate cycle and/or pentose phosphate cycling, these pathways account for only a small percentage $(<1-2 \%)$ of total glucose turnover (24). The production rate of ${ }^{3} \mathrm{H}_{2} \mathrm{O}$ was calculated from the increment per unit time in plasma tritiated water radioactivity $(\mathrm{dpm} / \mathrm{ml} \cdot \mathrm{min})$ multiplied by the total body water content, which was individually measured in all subjects. The increment in the rate of plasma ${ }^{3} \mathrm{H}_{2} \mathrm{O}$ appearance rate in plasma water was linear in all studies. The rate of total body glycolysis $(\mu \mathrm{mol} / \mathrm{min})$ was calculated by dividing the ${ }^{3} \mathrm{H}_{2} \mathrm{O}$ production rate $(\mathrm{dpm} / \mathrm{min})$ by the plasma $\left[{ }^{3} \mathrm{H}\right]-$ glucose specific activity $(\mathrm{dpm} / \mu \mathrm{mol})$. The difference between total glucose disposal rate and the glycolytic flux provides an estimate of the rate of glycogen synthesis. Validation of this approach has been provided recently in animals (25) and humans (Bonadonna, R. C., et al., manuscript submitted for publication). In animals, Rossetti et al. (25) have shown a very high degree of concordance between the rate of muscle glycogen deposition, as measured by the direct incorporation of $\left[{ }^{3} \mathrm{H}\right]$ glucose, and the value calculated from the difference between the rate of total body glucose disappearance and the rate of total glycolysis.

Total body water $(T B W)$. On a separate day, all subjects received an intravenous bolus of ${ }^{3} \mathrm{H}_{2} \mathrm{O}(50 \mu \mathrm{Ci})$ for the estimation of total body water. Blood samples were taken after 120,150, and $180 \mathrm{~min}$ for determination of plasma ${ }^{3} \mathrm{H}_{2} \mathrm{O}$ radioactivity. In the calculation of plasma ${ }^{3} \mathrm{H}_{2} \mathrm{O}$ specific activity, plasma water was assumed to represent $93 \%$ of total plasma volume. FFM was calculated by dividing total body water by 0.71 (19).

\section{Analytical procedures}

Arterialized venous blood samples were used for the determination of substrate and hormone concentrations and plasma specific activities. Immediately after collection, all samples were placed on ice, centrifuged at $4^{\circ} \mathrm{C}$, and the plasma frozen at $-20^{\circ} \mathrm{C}$ until determinations were performed. Plasma insulin concentration was determined by ra- 

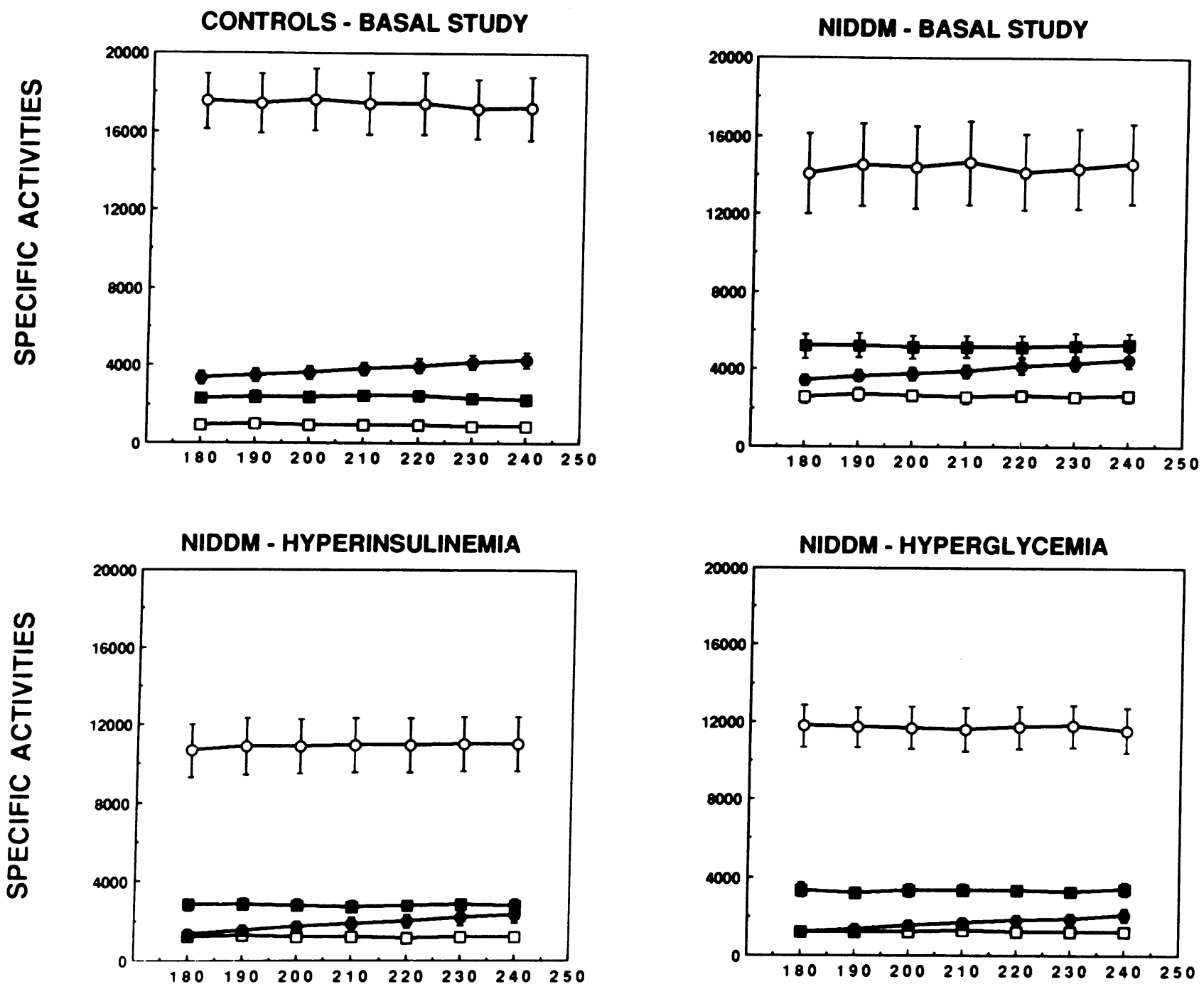

\section{TIME (min)}

Figure 1. Steady-state specific activities of plasma $3-\left[{ }^{3} \mathrm{H}\right]-$ and $\mathrm{U}-\left[{ }^{14} \mathrm{C}\right]$ glucose $(\bullet$, and $\square$, respectively; dpm/ $\mathrm{mg})$, plasma ${ }^{3} \mathrm{H}_{2} \mathrm{O}(\bullet ; \mathrm{dpm} / \mathrm{mmol})$, and expired ${ }^{14} \mathrm{CO}_{2}(\mathrm{O} ; \mathrm{dpm} / \mathrm{mmol})$ in control and NIDDM subjects under the different experimental conditions of the study.

dioimmunoassay technique (26). During the clamp studies, plasma glucose concentration was measured at bedside every 5-10 min by a Glucose Analyzer II (Beckman Instruments, Inc.). Plasma concentrations of FFA (27) and lactate (28) were determined by enzymatic assays.

A high-performance liquid chromatographic (HPLC) method was used for determination of $3-\left[{ }^{3} \mathrm{H}\right]$ - and $\mathrm{U}-\left[{ }^{14} \mathrm{C}\right]$ glucose specific activities. Briefly, $1 \mathrm{ml}$ of plasma was passed over an $\mathrm{X} 1-8$ resin which trapped all of $\left[{ }^{14} \mathrm{C}\right]$ lactate. Eluates were deproteinized according to Somogyi (29) and centrifuged for $20 \mathrm{~min}$ at $4,000 \mathrm{~g}$. The clear supernatant was evaporated to dryness in a Speed-Vac Evaporator (Savant Instruments, Inc., Farmindale, NY). Samples were reconstituted in HPLC-grade water and injected in a HPLC system (model 510 HPLC pump, Waters Associates, Milford, MA) with an Aminex ion-exclusion HPX-87H column (Bio-Rad Laboratories, Richmond, CA). The mobile phase was $0.02 \mathrm{~N} \mathrm{H}_{2} \mathrm{SO}_{4}$ at $0.55 \mathrm{ml} / \mathrm{min}$ flow rate. Retention time for glucose was $18 \mathrm{~min}$; a 6-min eluate was collected around that time (15-20 $\mathrm{min}$ ) and added to $10 \mathrm{ml}$ of scintillation liquid and counted in an automatic double-channel scintillation counter (LS 5000 Scintillation Counter, Beckman Instruments, Inc.) for determination of plasma $\left[{ }^{3} \mathrm{H}\right]-$ and $\left[{ }^{14} \mathrm{C}\right]$ glucose radioactivities. Elution peak was detected by a refractive index detector (Differential Refractometer 410, Waters Associates) and glucose concentration was calculated from a standard curve. The accuracy of the calibration curve was checked daily by injecting in the HPLC system an aliquot of the glucose standard utilized to calibrate the Beckman Glucose Analyzer II. Therefore, in the same plasma sample it was possible to measure radioactivity of $\left[{ }^{3} \mathrm{H}\right]-$ and $\left[{ }^{14} \mathrm{C}\right]$ glucose and the glucose concentration for calculation of their specific activities. An aliquot of the infusate also was processed as described above to determine the tracer purity and to calculate the tracer infusion rate. In no case was there any evidence for the presence of any radioactive species other than glucose either in the infusate or in the plasma samples. These results exclude any underestimation of the rates of glucose turnover from the accumulation in plasma of a nonglucose radioactive substance contained in the labeled glucose infusate (30). Consistent with this, we did not observe any negative number for HGP in any experimental condition (see results).

For determination of ${ }^{3} \mathrm{H}_{2} \mathrm{O}$ specific activity, 300- $\mu$ l plasma aliquots were pipetted into $1-\mathrm{ml}$ tubes which were placed inside a $20-\mathrm{ml}$ scintillation vial which contained $2 \mathrm{ml}$ of distilled water. The vials were tightly capped and ${ }^{3} \mathrm{H}_{2} \mathrm{O}$ water equilibration was allowed to occur by overnight heating $\left(50^{\circ} \mathrm{C}\right)$. After removal of the inner tube, $18 \mathrm{ml}$ of 
scintillation liquid was added into the vials and ${ }^{3} \mathrm{H}_{2} \mathrm{O}$ radioactivity was determined in an automatic scintillation counter. $50 \mu \mathrm{l}$ of the injected dose of ${ }^{3} \mathrm{H}_{2} \mathrm{O}$ that was used for the determination of total body water were added to $250 \mu \mathrm{l}$ of unlabeled water and processed as described above for calculation of the recovery factor.

\section{Calculations and statistical analysis}

All data represent the mean \pm SEM values over the last hour of each study. Statistical analysis was performed by Student's $t$ test and analysis of variance with repeated measures over time.

\section{Results}

Whole-body glucose disposal (Table III). In study 1, when NIDDM patients and normal subjects were studied at comparable plasma glucose $(5.1 \pm 0.2$ vs. $5.2 \pm 0.1 \mathrm{mM})$ and insulin $(258 \pm 24$ vs. $269 \pm 39 \mathrm{pM})$ concentrations, the rate of total body glucose utilization was $54 \%$ lower in the NIDDM patients $(18.8 \pm 1.1 \mu \mathrm{mol} / \mathrm{min} \cdot \mathrm{kg}$ FFM $)$ than in control individuals $(40.5 \pm 6.3 \mu \mathrm{mol} / \mathrm{min} \cdot \mathrm{kg}$ FFM; $P<0.01)$. In study 2 , the superimposition of hyperglycemia $(14.9 \pm 1.2 \mathrm{mM})$ on hyperinsulinemia $(259 \pm 19 \mathrm{pM})$ in NIDDM subjects resulted in an increase in the whole-body glucose disposal rate to $40.7 \pm 2.1$ $\mu \mathrm{mol} / \mathrm{min} \cdot \mathrm{kg}$ FFM, a value that was similar to that observed in control individuals $(P=\mathrm{NS})$. When euglycemia $(5.5 \pm 0.3$ $\mathrm{mM}$ ) was maintained and the plasma insulin concentration was increased to $1,650 \pm 529 \mathrm{pM}$, total body glucose uptake rose to a value $(40.7 \pm 1.7 \mu \mathrm{mol} / \mathrm{min} \cdot \mathrm{kg}$ FFM $)$, which was similar to the rate of glucose disposal in the normal individuals ( $P$ $=$ NS).

$H G P$ (Table III). In control subjects during insulin infusion, while maintaining euglycemia, HGP was $3.7 \pm 1.5 \mu \mathrm{mol} /$ $\mathrm{min} \cdot \mathrm{kg}$ FFM, a value that was slightly, but not significantly, lower than in NIDDM patients $(6.6 \pm 1.6 \mu \mathrm{mol} / \mathrm{min} \cdot \mathrm{kg}$ FFM $)$ studied under similar conditions. In NIDDM individuals, the superimposition of hyperglycemia (study 2 ) on the moderate hyperinsulinemia of study 1 did not cause a greater suppression of HGP $(6.7 \pm 1.1 \mu \mathrm{mol} / \mathrm{min} \cdot \mathrm{kg}$ FFM $)$. In study 3, a fivefold increase in plasma insulin concentration reduced HGP to $1.6 \pm 0.8 \mu \mathrm{mol} / \mathrm{min} \cdot \mathrm{kg} F F M$, a value that was significantly lower $(P<0.01)$ than obtained in control individuals.

Whole-body glycolysis (Table III). The insulin resistance in NIDDM patients (study 1 ) was associated with a $35 \%$ reduction in the rate of plasma glucose through the glycolytic path- way $(13.9 \pm 1.5$ vs. $21.6 \pm 2.3 \mu \mathrm{mol} / \mathrm{min} \cdot \mathrm{kg}$ FFM; $P<0.02)$. Normalization of total body glucose uptake by hyperglycemia (study 2) caused an increase in the glycolytic flux to a value $(19.7 \pm 2.0 \mu \mathrm{mol} / \mathrm{min} \cdot \mathrm{kg}$ FFM; $P<0.01$ vs. study 1$)$ that was not significantly different than observed in control subjects. Hyperinsulinemia (study 3 ) also normalized the glycolytic flux $(24.7 \pm 1.4 \mu \mathrm{mol} / \mathrm{min} \cdot \mathrm{kg}$ FFM; $P=\mathrm{NS}$ vs. controls $)$.

Glucose oxidation (Table III). The rate of plasma glucose oxidation was determined from the rate of appearance of ${ }^{14} \mathrm{CO}_{2}$ in expired air during the last 60 min of each study, when a steady-state condition existed for both carbon dioxide and plasma glucose specific activities (Fig. 1). In control subjects studied under conditions of euglycemia and moderate hyperinsulinemia, plasma glucose oxidation was $19.5 \pm 0.8 \mu \mathrm{mol} /$ $\mathrm{min} \cdot \mathrm{kg}$ FFM ( Table III). When NIDDM patients were evaluated under comparable conditions (study 1), plasma glucose oxidation was significantly impaired $(8.4 \pm 1.0 \mu \mathrm{mol} / \mathrm{min} \cdot \mathrm{kg}$ FFM; $P<0.001)$. When hyperglycemia was employed to normalize total body glucose utilization in NIDDM patients, plasma glucose oxidation increased to $13.5 \pm 0.7 \mu \mathrm{mol} / \mathrm{min} \cdot \mathrm{kg}$ FFM $(P<0.05)$. Nevertheless, this figure remained significantly lower than in control individuals $(P<0.01)$. When hyperinsulinemia (study 3 ) was used to normalize the rates of total body glucose uptake and glycolysis, the rate of plasma glucose oxidation increased significantly to $16.7 \pm 0.6 \mu \mathrm{mol} /$ min - kg FFM; however, this was still significantly less than observed in the normal group (Table III).

Gas exchange measurements obtained by indirect calorimetry provide an estimate of total carbohydrate oxidation. In NIDDM subjects, carbohydrate oxidation was significantly lower than in controls $(10.3 \pm 0.9$ vs. $21.6 \pm 0.9 \mu \mathrm{mol} / \mathrm{min} \cdot \mathrm{kg}$ FFM; $P<0.01$ ) when evaluated under conditions of euglycemic hyperinsulinemia. These results obtained with indirect calorimetry are very similar to those obtained from the isotopically determined oxidation of plasma glucose. Carbohydrate oxidation (measured with indirect calorimetry) increased when either hyperglycemia ( $16.4 \pm 1.3 \mu \mathrm{mol} / \mathrm{min} \cdot \mathrm{kg} \mathrm{FFM})$ or hyperinsulinemia $(17.6 \pm 1.1 \mu \mathrm{mol} / \mathrm{min} \cdot \mathrm{kg}$ FFM) were superimposed, but in neither situation did the oxidation rate reach values similar to those observed in the control group (both $P$ $<0.05$ ). Again, these results are similar to those obtained from oxidation of plasma glucose.

Nonoxidative glycolysis (Table III). The difference between the rate of plasma glucose through the glycolytic flux and

Table III. Absolute Rates of Glucose Metabolic Fluxes and Lipid Oxidation in Control Subjects and NIDDM Patients during the Last Hour of the Clamp Studies

\begin{tabular}{|c|c|c|c|c|c|c|c|}
\hline & $\begin{array}{l}\text { Glucose } \\
\text { disposal }\end{array}$ & HGP & $\begin{array}{l}\text { Glycogen } \\
\text { deposition }\end{array}$ & Glycolysis & $\begin{array}{c}\text { Glucose } \\
\text { oxidation }\end{array}$ & $\begin{array}{l}\text { Nonoxidative } \\
\text { glycolysis }\end{array}$ & $\begin{array}{l}\text { Lipid } \\
\text { oxidation }\end{array}$ \\
\hline & \multicolumn{7}{|c|}{$\mu \mathrm{mol} / \mathrm{min} \cdot \mathrm{kg} \mathrm{FFM}$} \\
\hline \multicolumn{8}{|l|}{ I. Controls } \\
\hline (20 mU insulin clamp) & $40.5 \pm 6.3$ & $3.7 \pm 1.5$ & $18.9 \pm 5.0$ & $21.6 \pm 2.3$ & $19.5 \pm 0.8$ & $2.1 \pm 0.8$ & $1.1 \pm 0.4$ \\
\hline \multicolumn{8}{|l|}{ II. NIDDM } \\
\hline (20 mU insulin clamp) & $18.8 \pm 1.1^{\ddagger}$ & $6.6 \pm 1.6$ & $4.8 \pm 0.9^{*}$ & $13.9 \pm 1.5^{*}$ & $8.4 \pm 1.0^{\S}$ & $5.5 \pm 2.1^{*}$ & $3.6 \pm 0.3^{8}$ \\
\hline \multicolumn{8}{|l|}{ III. NIDDM } \\
\hline (hyperglycemic clamp) & $40.7 \pm 2.1$ & $6.7 \pm 1.1^{*}$ & $20.9 \pm 3.0$ & $19.7 \pm 2.0$ & $13.5 \pm 0.7^{\ddagger}$ & $6.2 \pm 1.8^{*}$ & $2.5 \pm 0.5^{\ddagger}$ \\
\hline \multicolumn{8}{|l|}{ IV. NIDDM } \\
\hline (hyperinsulinemic clamp) & $40.7 \pm 1.7$ & $1.6 \pm 0.8^{\ddagger}$ & $15.9 \pm 1.3$ & $24.7 \pm 1.4$ & $16.7 \pm 0.6^{*}$ & $8.0 \pm 1.3^{\ddagger}$ & $0.9 \pm 0.2$ \\
\hline
\end{tabular}

${ }^{*} P<0.05 ;{ }^{\ddagger} P<0.01 ;{ }^{\S} P<0.001$ vs. controls. 
the plasma glucose oxidation provides an estimate of nonoxidative glycolysis. In normal individuals, nonoxidative glycolysis was $2.1 \pm 0.8 \mu \mathrm{mol} / \mathrm{min} \cdot \mathrm{kg}$ FFM and accounted for $10 \pm 3 \%$ of total glycolysis. In NIDDM patients studied at comparable levels of hyperinsulinemia and euglycemia (study 1 ), the rate of non-oxidative glycolysis was increased approximately threefold $(5.5 \pm 2.1 \mu \mathrm{mol} / \mathrm{min} \cdot \mathrm{kg} \mathrm{FFM} ; P<0.05)$. In these patients nonoxidative glycolysis accounted for $39 \pm 8 \%$ of total glycolysis $(P<0.02$ vs. controls). When the rate of plasma glucose utilization in NIDDM subjects was normalized by increasing the plasma glucose concentration, the absolute rate of nonoxidative glycolysis $(6.2 \pm 1.8 \mu \mathrm{mol} / \mathrm{min} \cdot \mathrm{kg}$ FFM $)$, as well as the percent of contribution of nonoxidative glycolysis to total glycolysis $(32 \pm 7 \%)$, remained unchanged from values observed in the same NIDDM patients during study 1 . When hyperinsulinemia was superimposed on euglycemia to normalize total body glucose uptake, there was a further increase in nonoxidative glycolysis $(8.0 \pm 1.3 \mu \mathrm{mol} / \mathrm{min} \cdot \mathrm{kg} \mathrm{FFM} ; P<0.05$ vs. controls) and the percent contribution to total glycolysis remained high $(31 \pm 4 \%)$.

Glycogen synthesis (Table III). The difference between total body glucose uptake (measured with tritiated glucose) and total glycolytic flux provides an estimate of the amount of plasma glucose stored in glycogen $(24,25)$. Under conditions of euglycemic hyperinsulinemia, glycogen synthesis occurred at a rate of $18.9 \pm 5.0 \mu \mathrm{mol} / \mathrm{min} \cdot \mathrm{kg} \mathrm{FFM}$ in normal subjects vs. $4.8 \pm 0.9 \mu \mathrm{mol} / \mathrm{min} \cdot \mathrm{kg}$ FFM $(P<0.05)$ in NIDDM patients. When total body glucose utilization was normalized by hyperglycemia (study 2), there was a significant increase in the rate of glycogen synthesis to $20.9 \pm 3.0 \mu \mathrm{mol} / \mathrm{min} \cdot \mathrm{kg}$ FFM ( $P$ $<0.05$ vs. basal study). When marked hyperinsulinemia was superimposed on euglycemia to normalize total body glucose uptake (study 3 ), glycogen synthesis $(15.9 \pm 1.3 \mu \mathrm{mol} / \mathrm{min} \cdot \mathrm{kg}$ FFM) increased to values that were slightly, although not significantly, different from those observed in normal individuals.

Intracellular distribution of insulin-mediated glucose uptake (Tables IV-VI and Fig. 2). The absolute rates of glucose utilization include the flux through both insulin-mediated and non-insulin-mediated pathways. The later primarily repre-

Table IV. Insulin-mediated Glucose Metabolic Fluxes in Control Subjects and NIDDM Patients

\begin{tabular}{llcc}
\hline $\begin{array}{c}\text { Glucose } \\
\text { disposal }\end{array}$ & Glycolysis & $\begin{array}{c}\text { Glycogen } \\
\text { deposition }\end{array}$ \\
\hline & $\mu \mathrm{mol} / \mathrm{min} \cdot \mathrm{kg} \mathrm{FFM}$
\end{tabular}
I. Controls
(20 mU insulin clamp)

\begin{abstract}
$33.8 \pm 6.3$
\end{abstract}
$14.9 \pm 2.3$
$18.9 \pm 5.0$
II. NIDDM
(20 mU insulin clamp)
III. NIDDM
$\begin{array}{lll}\text { (hyperglycemic clamp) } \quad 34.0 \pm 2.1 & 13.0 \pm 2.0 & 20.9 \pm 12.0\end{array}$
IV. NIDDM
$\begin{array}{llll}\text { (hyperinsulinemic clamp) } \quad 34.0 \pm 1.7 & 18.0 \pm 1.4 & 15.9 \pm 1.3\end{array}$

The rate of non-insulin-mediated glucose disposal $(6.7 \mu \mathrm{mol} / \mathrm{min} / \mathrm{kg}$ FFM) has been subtracted from the rates of the total body glucose disposal and glycolysis to obtain insulin-mediated flux rates. Because no glycogen synthesis is assumed to occur in non-insulin-dependent tissues (brain) nothing was subtracted from the rate of total body glycogen deposition. ${ }^{*} P<0.05 ;{ }^{\ddagger} P<0.01$ vs. control subjects.
Table V. Insulin-stimulated Glucose Fluxes Expressed as Percentage of Insulin-mediated Glucose Uptake in Control Subjects and NIDDM Patients

\begin{tabular}{ccc}
\hline & Glycolysis & $\begin{array}{c}\text { Glycogen } \\
\text { deposition }\end{array}$ \\
\hline & $\%$ & $\%$ \\
I. Controls (20 mU insulin clamp) & $44 \pm 4$ & $56 \pm 4$ \\
II. NIDDM (20 mU insulin clamp) & $58 \pm 8$ & $42 \pm 8$ \\
III. NIDDM (hyperglycemic clamp) & $39 \pm 7$ & $61 \pm 7$ \\
IV. NIDDM (hyperinsulinemic clamp) & $53 \pm 3$ & $47 \pm 3$ \\
\hline
\end{tabular}

All data are expressed as percentage of insulin-mediated glucose disposal (see Table IV).

sents brain glucose uptake and subsequent oxidation to carbon dioxide and water $(31,32)$. To estimate the metabolic component of glucose uptake which is insulin-mediated, an average value of $6.7 \mu \mathrm{mol} / \mathrm{min} \cdot \mathrm{kg}$ FFM $(31,32)$ for brain glucose oxidation was subtracted from the rate of total body glucose utilization, as well as from the rates of glycolysis and glucose oxidation. When the data are expressed as a percentage of the rate of total insulin-mediated glucose disposal (Tables IV and VI), it is apparent that in NIDDM patients the percentage of total glucose flux entering the two main pathways of intracellular glucose metabolism, i.e., glycogen synthesis and glycolysis, is similar to control subjects. Under all the experimental conditions reported in the present paper each of the two pathways accounted for $\sim 50 \%$ of the total insulin-mediated glucose uptake ( Table V). A similar analysis of the two main branches of the glycolytic pathway, i.e., glucose oxidation and nonoxidative glycolysis ( Table VI and Fig. 2), revealed an entirely different picture. In all three clamp studies performed in NIDDM patients, a major unbalance was observed with a disproportionately greater flux into the nonoxidative pathway and a reduced flux into the Krebs cycle, i.e., oxidation, as compared to normal subjects (Table VI, Fig. 2).

Table VI. Insulin-stimulated Glucose Fluxes in Control Subjects and NIDDM Patients

\begin{tabular}{lccc}
\hline & Glycolysis & $\begin{array}{c}\text { Glucose } \\
\text { oxidation }\end{array}$ & $\begin{array}{c}\text { Nonoxidative } \\
\text { glycolysis }\end{array}$ \\
\hline & & $\mu \mathrm{mol} / \mathrm{min} \cdot \mathrm{kg} F F M$ \\
& & & \\
& & & \\
$\begin{array}{l}\text { I. Controls } \\
\text { (20 mU insulin clamp) }\end{array}$ & $14.9 \pm 2.3$ & $12.8 \pm 0.8$ & $2.1 \pm 0.8$ \\
$\begin{array}{l}\text { II. NIDDM } \\
\quad(20 \mathrm{mU} \text { insulin clamp) }\end{array}$ & $7.2 \pm 1.5^{*}$ & $1.7 \pm 1.0^{\ddagger}$ & $5.5 \pm 2.1^{*}$ \\
$\begin{array}{l}\text { III. NIDDM } \\
\text { (hyperglycemic clamp) }\end{array}$ & $13.0 \pm 2.0$ & $6.8 \pm 0.7^{\S}$ & $6.2 \pm 1.8^{*}$ \\
$\begin{array}{l}\text { IV. NIDDM } \\
\text { (hyperinsulinemic clamp) }\end{array}$ & $18.0 \pm 1.4$ & $10.0 \pm 0.7^{*}$ & $8.0 \pm 1.3^{\S}$ \\
\hline
\end{tabular}

The rate of non-insulin-mediated glucose disposal $(6.7 \mu \mathrm{mol} / \mathrm{min} / \mathrm{kg}$ FFM) has been subtracted from the rates of total body glucose disposal and glycolysis to obtain insulin-mediated flux rates. Because no glycogen synthesis is assumed to occur in non-insulin-dependent tissues (brain) nothing was subtracted from the rate of total body glycogen deposition. ${ }^{*} P<0.05 ;{ }^{\ddagger} P<0.02 ;{ }^{\S} P<0.01$ vs. control subjects. 


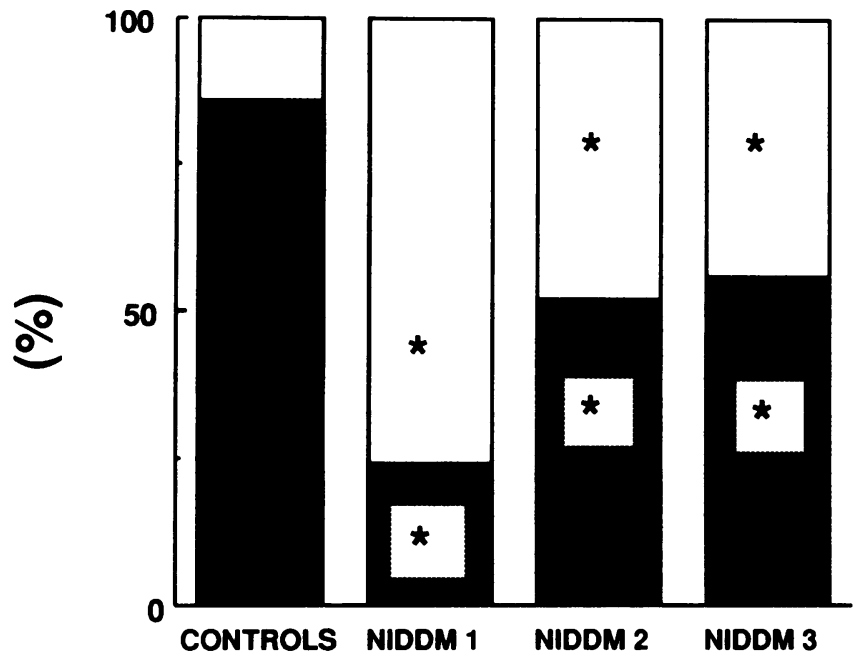

Figure 2. Percent distribution of total glycolysis (total height of each bar) into glucose oxidation (open portion of each bar) and nonoxidative glycolysis (solid portion of each bar) in control subjects and in NIDDM patients during euglycemia plus moderate hyperinsulinemia (study 1), hyperglycemia plus moderate hyperinsulinemia (study 2), and euglycemia plus marked hyperinsulinemia (study 3 ). The results are expressed as a percentage of insulin-stimulated glucose utilization; ${ }^{*} P<0.05$ vs. control individuals.

Lipid oxidation (Table III). Gas exchange measurements during each experimental protocol were used to calculate the rate of lipid oxidation. In NIDDM subjects during the euglycemic hyperinsulinemic clamp, lipid oxidation $(3.6 \pm 0.3 \mu \mathrm{mol} /$ $\mathrm{min} \cdot \mathrm{kg}$ FFM $P<0.001)$ was threefold higher than in control individuals $(1.1 \pm 0.4 \mu \mathrm{mol} / \mathrm{min} \cdot \mathrm{kg} F \mathrm{FM})$. Normalization of glucose disposal by hyperglycemia (study 2 ) was associated with a decline in lipid oxidation to $2.5 \pm 0.5 \mu \mathrm{mol} / \mathrm{min} \cdot \mathrm{kg}$ FFM; however, this value was still higher than that in the control group $(P<0.01)$. Lipid oxidation was completely returned to normal $(0.9 \pm 0.2 \mu \mathrm{mol} / \mathrm{min} \cdot \mathrm{kg}$ FFM $)$ only in the presence of marked hyperinsulinemia (study 3 ). When the relationship between lipid oxidation and parameters of glucose metabolism were analyzed in the whole study population, negative correlations were apparent with respect to total body glycolysis $(r$ $=0.65)$ and glucose oxidation $(r=0.75$; both $P<0.01$; Fig. 3 ). No correlation between lipid oxidation and glycogen synthesis was observed.

Plasma FFA and lactate concentration (Table II). During the postabsorptive state, the plasma FFA $(0.83 \pm 0.06$ vs. $0.62 \pm 0.07 \mathrm{mM} ; P<0.05)$ and plasma lactate $(1.31 \pm 0.12$ vs. $0.79 \pm 0.07 \mathrm{mM} ; P<0.01$ ) concentrations were significantly increased in NIDDM vs. control subjects (Table II). The mean plasma lactate and FFA concentrations during the last hour of each experimental condition are shown in Table II. In response to euglycemic hyperinsulinemia, plasma FFA declined both in control and NIDDM patients. However, plasma FFA suppression was significantly less in NIDDM vs. controls $(P<0.02)$. A further suppression of plasma FFA level was observed after marked increases in both steady-state plasma glucose (study 2) or insulin (study 3 ) concentrations. Nevertheless, the average plasma FFA levels remained slightly higher in the NIDDM patients than in control individuals $(P<0.05)$. No significant changes in plasma lactate concentration occurred during the $20-\mathrm{mU} / \mathrm{m}^{2} \cdot \mathrm{min}$ insulin clamp study in either control or
NIDDM subjects and the plasma lactate concentration remained significantly elevated in the latter group $(P<0.01)$. There was a slight decline in the plasma lactate concentration in NIDDM subjects during study 2 (hyperglycemia) and study 3 (marked hyperinsulinemia), but the levels still remained greater than those in control subjects.

\section{Discussion}

When NIDDM and control subjects were studied at similar plasma insulin and glucose concentrations, whole-body glucose uptake was reduced by $54 \%$. The results obtained from our laboratory (11) and others $(10,14)$, which have employed the insulin clamp with indirect calorimetry, have shown a reduction in both oxidative and nonoxidative glucose metabolism. Nonoxidative glucose metabolism has been used as an index of glycogen synthesis $(12,13)$. However, nonoxidative glucose metabolism actually is composed of glucose which is glycolyzed but not oxidized, i.e., nonoxidative glycolysis, as well as glycogen synthesis (33). Therefore, direct measurement of the glycolytic flux allows a more reliable determination of the amount of glucose which is directed toward glycogen synthesis. In the present study, glycogen deposition in NIDDM was reduced by $75 \%$, a figure that is in agreement with data obtained with indirect calorimetry $(11,33)$ and nuclear mag-

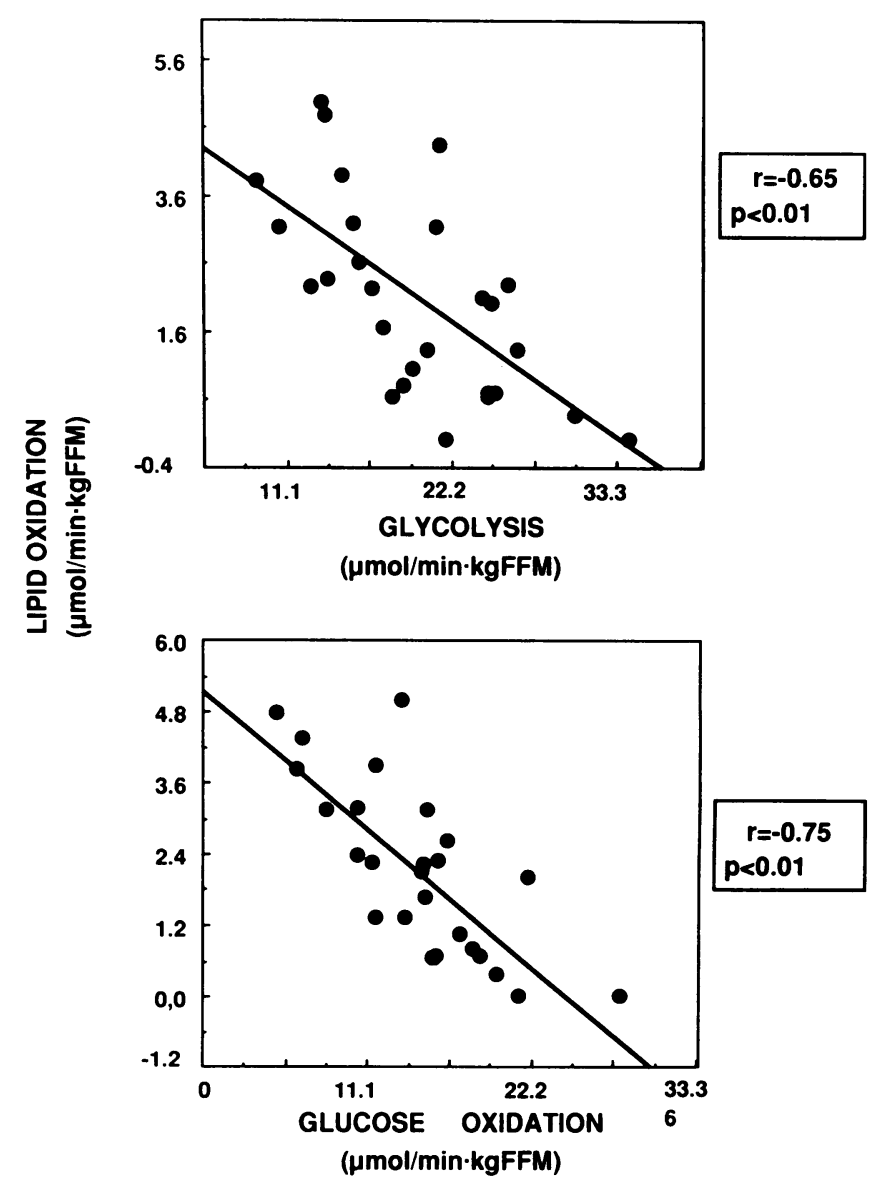

Figure 3. Correlation between lipid oxidation and glycolytic flux (top panel) and glucose oxidation rate (bottom panel) in both control and NIDDM subjects studied under all experimental conditions. 
netic resonance spectroscopy (34) and is consistent with the documented reduction in glycogen synthase activity reported in NIDDM patients $(35,36)$. Our results also demonstrate that the rates of total glycolytic flux and glucose oxidation were significantly reduced in the diabetic group by $36 \%$ and $57 \%$, respectively. The simultaneous assessment of total glycolysis and glucose oxidation allows the calculation of nonoxidative glycolysis, which was significantly increased in NIDDM patients ( Table III). Consistent with this observation, the plasma lactate concentration also was significantly higher in NIDDM patients than in control individuals (Table II).

An overall picture of the disposition of plasma glucose that is taken up by cells under conditions of euglycemia and physiologic hyperinsulinemia indicates that, from the quantitative standpoint, the impairment in glycogen synthesis in NIDDM patients ( $4.8 \mathrm{vs}$. $18.9 \mu \mathrm{mol} / \mathrm{min} \cdot \mathrm{kg} \mathrm{FFM} ; \Delta=14.1$ ) is approximately twofold greater than the impairment in total body glycolysis (13.9 vs. $21.6 \mu \mathrm{mol} / \mathrm{min} \cdot \mathrm{kg} \mathrm{FFM;} \Delta=7.7$ ). On a percent basis, glycogen synthesis and glycolysis accounted for $47 \%$ and $57 \%$, respectively, of total body glucose uptake in control subjects, whereas this ratio was shifted to $26 \%$ and $74 \%$, respectively, in NIDDM patients. It is noteworthy that glucose oxidation, while reduced in diabetic patients (8.4 vs. 19.5 $\mu \mathrm{mol} / \mathrm{min} \cdot \mathrm{kg} \mathrm{FFM}$ ), accounted for $52 \%$ of total glucose uptake and that this percentage was similar to that observed in control individuals (45\%). However, if one examines the contribution of glucose oxidation to total glycolytic flux, a very different picture emerges. In the control group, $90 \%$ of the glycolytic flux was accounted for by glucose oxidation, whereas in NIDDM patients glucose oxidation represented only $60 \%$ of the glycolytic flux $(P<0.05)$. Conversely, nonoxidative glycolysis was responsible for only $10 \%$ of total glycolysis in the control subjects, while in NIDDM patients it accounted for $40 \%$. This important observation concerning differences in the intracellular portioning of glucose between NIDDM and control subjects could not be recognized by previous studies which only employed indirect calorimetry. The disproportionate decrease in glucose oxidation and increase in nonoxidative glycolysis in NIDDM patients which was detected by the dual-isotope technique, suggests the presence of a distal defect in the glycolytic pathway, most likely at the level of pyruvate dehydrogenase $(36,37)$. If an early defect in glycolysis were present, one would expect proportionate decreases in both glucose oxidation and nonoxidative glycolysis.

It should be emphasized that the above calculations are based upon whole-body rates of glucose uptake and assume that all of the glycolytic/oxidative flux during the insulin clamp occurs in insulin-dependent tissues. However, this clearly is not the situation since, in the postabsorptive state, the brain oxidizes glucose at a constant rate of $6.7 \mu \mathrm{mol} / \mathrm{min} \cdot \mathrm{kg}$ FFM $(31,32)$ and this basal rate of brain glucose oxidation is not affected by insulin. Therefore, when examining the relative fluxes of insulin-mediated glucose through the oxidative/glycolytic and glycogen synthetic pathways during insulin stimulated conditions, it is appropriate to subtract this fixed insulinindependent rate of glucose oxidation $(6.7 \mu \mathrm{mol} / \mathrm{min} \cdot \mathrm{kg}$ FFM) from the rate of total glucose uptake and glucose oxidation/glycolysis (Tables IV-VI, and Fig. 2). When the data are calculated in this manner, the percentage of total plasma glucose uptake that enters the glycogen synthetic pathway in response to the increment in plasma insulin concentration no longer is significantly different between diabetic and control subjects ( $56 \%$ vs. $44 \% ; P=\mathrm{NS}$ ). A similar distribution of the glucose flux between glycogen synthesis and glycolysis suggests that the rate limiting step for insulin-mediated plasma glucose utilization, at least under the conditions of moderate hyperinsulinemia and euglycemia, resides at an early step in the cellular mechanism of insulin action, i.e., glucose transport or glucose phosphorylation. This view is consistent with the demonstration of a reduction in glucose transport activity in adipocytes in NIDDM individuals (38) and muscle fibers (39) from NIDDM individuals, and with recent studies that have examined insulin-stimulated glucose transport in the forearm of NIDDM patients (40).

To gain further insight concerning the alteration in intracellular glucose metabolism, we have examined the intracellular pathways involved in glucose metabolism after total body glucose utilization was matched in NIDDM and normal individuals either by increasing the plasma glucose concentration (to $15 \mathrm{mM}$ ) or by markedly increasing the plasma insulin level (to $1,650 \mathrm{pM}$ ). When hyperglycemia was used to normalize the rate of total body glucose uptake in NIDDM patients, the intracellular disturbances in glucose metabolism were not normalized. Although the total glycolytic flux increased to a rate which was similar to that observed in control subjects during the euglycemic hyperinsulinemic clamp (study 1 ), glucose oxidation remained significantly lower than in controls (Table III) while nonoxidative glycolysis remained significantly elevated. These differences are unlikely to be explained by a shift in the contribution of different tissues to whole-body glucose disposal in response to hyperinsulinemia or hyperglycemia since we $(9$, $41)$, as well as others $(37,42)$, have shown that muscle represents the primary tissue responsible for the disposal of the majority ( $>75-80 \%$ ) of a glucose load in response to both those physiologic stimuli. Moreover, neither the splanchnic (43) nor the neural tissue (44) are responsive to insulin. Although hyperglycemia per se may augment splanchnic glucose uptake (43), from the quantitative standpoint this effect is small and under conditions comparable to those employed in the present study, we have shown that an increase in splanchnic glucose uptake can account for no more than 10-15\% of the total body glucose disposal. This is quite small when viewed in terms of the $50 \%$ lower rate of whole-body glucose utilization observed in NIDDM subjects in the present study.

A number of investigators (16-18, 37, 45), including ourselves (15), have demonstrated that hyperglycemia, both in the fasting and insulin-stimulated states, is capable of maintaining a normal rate of total body glucose utilization. The present findings are in agreement with these previous observations, but document that hyperglycemia is not capable of overcoming the intracellular defect in glucose oxidation. This finding is in agreement with the reported reduction in the activity of pyruvate dehydrogenase in NIDDM subjects (36). Furthermore, the inability of hyperglycemia to correct the defect in glucose oxidation despite a normalization of total glucose uptake indicates that $(a)$ the impairment in glucose oxidation cannot be explained by a defect in glucose transport, and $(b)$ insulin, and not glucose flux or hyperglycemia, is the main regulator of intracellular glucose oxidation (45). Consistent with this hypothesis, supraphysiologic hyperinsulinemia (study 3 ) further enhanced glucose oxidation (Table III). However, even with supraphysiologic plasma insulin concentrations, glucose oxi- 
dation did not return completely to normal (16.7 vs. 19.5 $\mu \mathrm{mol} / \mathrm{min} \cdot \mathrm{kg}$ FFM; $P<0.05)$. The inability of even marked hyperinsulinemia to totally correct the defect in glucose oxidation can be better appreciated if one examines both the total glycolytic flux and the partitioning of this flux between glucose oxidation and nonoxidative glycolysis. The total glycolytic flux in NIDDM patients during the high-dose insulin clamp increased modestly compared to controls ( 24.7 vs. $21.6 \mu \mathrm{mol} /$ $\mathrm{min} \cdot \mathrm{kg}$ FFM; Table III). Despite this higher total glycolytic flux the absolute rate of plasma glucose oxidation in NIDDM patients ( 16.7 vs. 19.5) was lower than in controls (Table III). A similar conclusion is reached if one calculates the insulinmediated glycolytic and oxidative fluxes (Table VI). These results are graphically represented in Fig. 2, which demonstrates that the percentage of total glycolytic flux accounted for by glucose oxidation was markedly reduced in NIDDM vs control subjects ( $68 \%$ vs. $90 \%, P<0.01$ ). Conversely, the percentage of the total glycolytic flux accounted for by nonoxidative glycolysis was increased threefold in NIDDM vs control individuals ( $32 \%$ vs. $10 \%, P<0.01$ ). This analysis provides convincing evidence for the presence of an intracellular defect in glucose oxidation, most likely at the level of pyruvate dehydrogenase (PDH). Moreover, this intracellular defect cannot be overcome, even when total glucose flux into the cell is normalized with hyperglycemia or with hyperinsulinemia (Table III and Fig. 2).

Recently, Kelley and Mandarino (37) have published the results of studies which are similar to those carried out by us reported here. In their study, they reported that insulin infusion, while clamping the plasma glucose concentration of NIDDM patients at their fasting hyperglycemic levels, was sufficient to normalize all aspects of glucose metabolism and muscle PDH activity. These results may, at first glance, appear contradictory to the present ones. However, there are two notable differences between the study design employed by Kelley and Mandarino (37) vs. ours. First, they examined leg, rather than whole-body glucose disposal. Second, the absolute rates of whole-body ( 330 vs. $234 \mathrm{mg} / \mathrm{m}^{2} \cdot \min , P<0.06$ ) and leg glucose utilization ( 8.06 vs. $5.64 \mu \mathrm{mol} / \mathrm{min} \cdot 100 \mathrm{ml}$ leg tissue, $P$ $=0.06$ ) in the NIDDM patients studied by Kelley and Mandarino (37) were $30 \%$ higher than in controls. Thus, they have more than normalized total leg glucose uptake in NIDDM group. If one recalculates their data by reducing the total leg glucose uptake by $30 \%$ in their diabetic patients (i.e., to actually match the rate of leg glucose uptake with the controls) and if one assumes a similar and parallel $30 \%$ reduction in all of the intracellular pathways of glucose metabolism, their results demonstrate a reduced rate of leg glucose oxidation ( 1.74 vs. 2.18 $\mu \mathrm{mol} / \mathrm{min}$ per $100 \mathrm{ml}$ of leg tissue) and an increased rate of glycogen storage $(3.53 \mathrm{vs} .2 .83 \mu \mathrm{mol} / \mathrm{min}$ per $100 \mathrm{ml}$ of leg tissue) in NIDDM vs. control subjects. Lastly, the plasma insulin concentration ( $468 \mathrm{pM}$ ) in their study was $70 \%$ higher than in the present study. This greater degree of hyperinsulinemia, in combination with a greatly increased substrate flux in NIDDM compared to control subjects, may well have overcome the defect in PDH activity.

During study 1 , when modest hyperinsulinemia was created in the presence of euglycemia, the suppression of plasma FFA concentration (Table II) and lipid oxidation (Table III) was impaired. The reduced suppression of plasma FFA could not be overcome by supraphysiologic insulin concentrations, while lipid oxidation was restored to normal. These results are consistent with those recently published by us (46). In that study we demonstrated that plasma FFA oxidation is primarily determined by the plasma FFA concentration, whereas intracellular lipid oxidation is primarily determined by the plasma insulin level (46). Thus, it is not surprising that hyperglycemia, while lowering the plasma FFA concentration to near normal levels, had little effect on lipid oxidation (Table III). In contrast, hyperinsulinemia, not only caused a major reduction in the plasma levels of FFA, but also completely normalized the rate of lipid oxidation. This may also suggest that under physiologic conditions of euglycemic hyperinsulinemia (study 1), part of the block at the PDH level in NIDDM patients may be explained by increased rate of FFA/lipid oxidation (47). This is consistent with the inverse relationship between lipid oxidation and both total glycolysis and glucose oxidation (Fig. 3). When the plasma FFA concentration and lipid oxidation were suppressed by insulin, relief of the inhibition of PDH could explain, in part, the increase in glucose oxidation.

The presence of an intracellular defect in glucose oxidation in NIDDM patients has previously been suggested by Thorburn et al. (48). After normalization of whole-body glucose disposal in NIDDM with insulin and hyperglycemia, they demonstrated a persistent defect in glucose oxidation and an inappropriate stimulation of nonoxidative glycolysis, although glycogen synthesis returned to a value that was not significantly different from controls. In the present study we have confirmed their results and provided stronger support for their finding by employing more sophisticated methodology. The conclusions of Thorburn et al. (48) relied heavily upon the increase in plasma lactate concentration to provide a measure of increased non-oxidative glycolysis in muscle. However, as shown by Kelley and Mardarino (37), even under conditions of hyperglycemia, no significant amount of lactate is released by muscle, indicating that tissue(s) other than muscle or different mechanisms (i.e., reduced lactate utilization) are responsible for the increase in plasma lactate concentration. Moreover, we are unaware of any data that demonstrate that changes in plasma lactate concentration reflect changes in lactate turnover either at the whole body level or in muscle. Even if such a relationship were to exist, it is unknown whether stimulation of glucose metabolism with hyperglycemia and hyperinsulinemia has similar effects on this relationship and whether this relationship is altered by the diabetic state. For all of these reasons it is difficult to equate changes in plasma lactate concentration with changes in lactate turnover. On the contrary, the radioisotopic methodology employed in the present study allows a direct assessment of the components of nonoxidative glucose metabolism, namely nonoxidative glycolysis. Therefore, what was extrapolated from data by Thoburn et al. (48) now has been directly measured in our study. The two studies together strongly support the hypothesis that, in NIDDM, intracellular defects distal to glucose transport are also present and that this defect primarily involves a decrease in glucose oxidation and a parallel increase in non-oxidative glycolysis.

Both the conclusions of Thorburn et al. (48) and our own are at variance with those of Butler et al. (49). These authors calculated the oxidation rate of intracellularly derived glucose as the difference between total (i.e., plasma plus intracellular glucose as measured by indirect calorimetry) and plasma glucose (derived from ${ }^{14} \mathrm{CO}_{2}$ generation from plasma $\left[{ }^{14} \mathrm{C}\right]-$ 
glucose) in NIDDM patients and control individuals under condition of moderate and supraphysiologic hyperinsulinemia. Since no difference was found in the rate of oxidation of intracellularly derived glucose between control and NIDDM patients, they argued that the mitochondrial oxidative pathway was normally responsive to insulin in NIDDM patients and, therefore, a more proximal defect such as glucose transport and/or phosphorylation was responsible of the decrease in plasma glucose oxidation. According to their interpretation whenever the proximal defect is bypassed and intracellular glucose oxidation is negligible, plasma glucose oxidation should be similar to that observed in control subjects, a hypothesis that was not directly tested by Butler et al. (49) and that is not supported by our results.

Finally, some considerations concerning the suppression of HGP are warranted. During study 1 in NIDDM patients, when euglycemia was maintained in the face of moderate physiologic hyperinsulinemia, HGP remained significantly higher than in control individuals ( Table III), indicating resistance to the suppressive action of insulin $(4,50)$. When hyperglycemia $(\sim 16$ $\mathrm{mM}$ ) was superimposed upon modest hyperinsulinemia (study 2), suppression of HGP was still impaired compared to controls and did not differ from that in study 1. It should pointed out that in normal subjects the presence of a similar degree of combined hyperglycemia and hyperinsulinemia causes a complete shut-off of HGP (11). These observations may have important clinical relevance since they suggest that even under the extreme conditions of hyperglycemia and hyperinsulinemia, i.e., after the ingestion of a meal, the liver contributes significantly to the maintenance of impaired glucose intolerance $(51,52)$.

In summary, our data provide evidence that in NIDDM patients with moderately severe fasting hyperglycemia, a defect in the intracellular metabolic fate of plasma glucose, i.e., specifically in the partitioning of glycolytic flux between glucose oxidation and nonoxidative glycolysis is present, and that this defect cannot be explained by an alteration in plasma glucose uptake. The observation that the rates of insulin-mediated glycolytic flux are proportionately reduced is consistent with an early defect in glucose metabolism, i.e., transport or phosphorylation, but does not exclude primary, parallel and quantitatively similar intracellular defects in both the glycogen synthetic and glycolytic pathways of poorly controlled NIDDM patients. It is, however, important to emphasize that without quantitative information concerning intracellular substrate concentrations, our results cannot identify the rate limiting step(s) for insulin-mediated glucose metabolism either in control or in NIDDM individuals. Finally, our results do not exclude a major defect in the glycogen synthetic pathway, which has been claimed to play a main role in the insulin resistance of NIDDM patients $(35,50,51,53,54)$. It should be recalled that (a) a significant difference in glycogen deposition was fully apparent in NIDDM patients studied at plasma insulin and glucose concentrations similar to control subjects, and $(b)$ the rate of glycogen deposition in NIDDM patients could be normalized only at the expense of marked hyperglycemia or hyperinsulinemia. In summary our findings clearly point out that in well-established NIDDM there are alterations in glucose metabolism that go far behind the reduction in insulin-stimulated glucose transport, and indicate that even the compensatory role of the mass action effect of hyperglycemia to ensure a "normal" rate of total body glucose utilization is associated with profound disturbances in the intracellular fate of glucose.

\section{Acknowledgments}

The authors would like to thank the nursing staff (Rita Mirabelli, Debra Mitchell, and Barbara Washington) of the Diabetes Research Unit of the General Clinical Research Center for their expertise in helping to perform these metabolic investigations. Ronald Klein, Christopher Carrol, Anna Pittard, and Cynthia Arzola-Munoz were responsible for carrying out the many analytical determinations. Lorrie Olivarri and Sheri Contero provided secretarial assistance in preparation of the manuscript.

This work was supported by National Institutes of Health grant DK-24092, a VA Merit Award, General Clinical Research Center grant M01-RR-013436, the General Research \& Educational Clinical Center, and the VA Medical Research Service. Dr. Stefano Del Prato was on leave from the Cattedra di Malattie del Ricambio, University of Padua, Italy. Dr. Giovanni Gulli was the recipient of a Mentor Based Fellowship Award from the American Diabetes Association and Drs. Riccardo C. Bonadonna and Myron Shank were recipients of a fellowship from the Juvenile Diabetes Foundation.

\section{References}

1. Kimmerling, G., C. Javorski, J. M. Olefsky, and G. Reaven. 1976. Demonstration of insulin resistance in untreated adult-onset diabetic subjects with fasting hyperglycemia. Diabetes. 25:673-678.

2. Rizza, R., L. Mandarino, and J. Gerich. 1981. Mechanism and significance of insulin resistance in non-insulin dependent diabetes mellitus. Diabetes. 30:990-995.

3. Bogardus, C., S. Lillioja, B. V. Howard, G. Reaven, and D. Mott. 1984. Relationships between insulin secretion, insulin action, and fasting plasma glucose concentration in nondiabetic and noninsulin-dependent diabetic subjects. $J$. Clin. Invest. 74:1238-1246.

4. De Fronzo, R. A. 1988. The triumvirate: beta cell, muscle, liver: a collusion responsible for NIDDM. Diabetes. 37:667-687.

5. Arner, P., T. Pollare, H. Lithell, and J. N. Livingston. 1987. Defective insulin receptor tyrosine kinase in human skeletal muscle in obesity and type II (non-insulin-dependent) diabetes mellitus. Diabetologia. 30:437-440.

6. Dohm, G. L. 1987. Insulin receptor kinase in human skeletal muscle from obese subjects with and without non-insulin-dependent diabetes. J. Clin. Invest. 79:1330-1337.

7. Kolterman, O. G., R. S. Gray, J. Griffin, P. Burstein, J. Insel, J. A. Scarlett, and J. M. Olefsky. 1981. Receptor and post-receptor defects contribute to the insulin resistance in non-insulin-dependent diabetes mellitus. J. Clin. Invest. 68:957-969.

8. Olefsky, J. M., and O. G. Kolterman. 1981. Mechanisms of insulin resistance in obesity and non-insulin-dependent (type II) diabetes. Am. J. Med. 70:151-168.

9. De Fronzo, R. A., E. Jacot, E. Jequier, E. Maeder, J. Wahren, and J. P. Felber. 1981. The effect of insulin on the disposal of intravenous glucose: results from indirect calorimetry and hepatic and femoral venous catheterization. Diabetes. 30:1000-1007.

10. Golay, A., R. A. De Fronzo, E. Ferrannini, D. C. Simonson, D. Thorin, K Achenson, E. Thiebaud, B. Curchod, E. Jequier, and J. P. Felber. 1988. Oxidative and non-oxidative metabolism in non-obese type 2 (non-insulin-dependent) diabetic patients. Diabetologia. 31:585-591.

11. Groop, L., R. C. Bonadonna, S. Del Prato, K. Ratheiser, K. Zick, E. Ferrannini, and R. A. De Fronzo. 1989. Glucose and free fatty acid metabolism in non-insulin-dependent diabetes mellitus: evidence for multiple sites of insulin resistance. J. Clin. Invest. 84:205-213.

12. Lillioja, S., D. M. Mott, J. K. Zawadzki, A. A. Young, W. G. Abbott, and C. Bogardus. 1986. Glucose storage is a major determinant of in vivo "insulin resistance" in subjects with normal glucose tolerance. J. Clin. Endocrinol. Metab. 62:922-927.

13. Mandarino, L. J., K. S. Wright, L. S. Verity, J. Nichols, J. M. Bell, O. G. Kolterman, and H. Beck-Nielsen. 1987. Effects of insulin infusion on human skeletal muscle pyruvate dehydrogenase, phosphofructokinase, and glycogen synthase: evidence for their role in oxidative and nonoxidative glucose metabolism. J. Clin. Invest. 80:655-663.

14. Felber, J. P., A. Golay, C. Felley, and E. Jequier. 1988. Regulation of glucose storage in obesity and diabetes: metabolic aspects. Diabetes Metab. Rev. 4:691-700. 
15. De Fronzo, R. A., E. Ferrannini, and V. Koivisto. 1983. New concepts in the pathogenesis and treatment of non-insulin-dependent diabetes mellitus. Am J. Med. 74(Suppl. 1):52-81.

16. Revers, R. R., R. Fink, J. Griffin, J. M. Olefsky, and O. G. Kolterman. 1984. Influence of hyperglycemia on insulin's in vivo effects in type II diabetes. $J$. Clin. Invest. 73:664-672.

17. Edelman, S. V., M. Laakso, P. Wallace, G. Brechtel, J. M. Olefsky, and A. Baron. 1990. Kinetics of insulin-mediated and non-insulin-mediated glucose up take in humans. Diabetes. 39:955-964.

18. Baron, A., M. Laakso, G. Brechtel, and S. V. Edelman. 1991. Reduced capacity and affinity of skeletal muscle for insulin-mediated glucose uptake in noninsulin-dependent diabetic subjects: Effects of insulin therapy. J. Clin. Invest. 87:1186-1194.

19. Schoeller, D. A., E. Van Santen, D. W. Peterson, W. Dietz, J. Jaspan, and P. D. Klein. 1980. Total body water measurement in humans with ${ }^{18} \mathrm{O}$ - and ${ }^{2} \mathrm{H}$ labeled water. Am. J. Clin. Nutr. 33:2686-2693.

20. De Fronzo, R. A., J. D. Tobin, and R. Andres. 1979. Glucose clamp technique: a method for quantifying insulin secretion and resistance. Am. J. Physiol. 237:E214-E223.

21. Simonson, D. C., and R. A. De Fronzo. 19XX. Indirect calorimetry: methodological and interpretative problems. Am. J. Physiol. 258:E399-E412.

22. Ferrannini, E., S. Del Prato, and R. A. De Fronzo. 1986. Glucose kinetics: tracer techniques. In Methods in Diabetes Research. Volume II. W. Z. Clarke, J. Larner, and S. L. Pohl, editors. John Wiley \& Son, Inc., New York. 107-142.

23. Wolfe, R. R. 1984. Bicarbonate kinetics and natural enrichment. In Tracers in Metabolic Research. Radioisotope and Stable Isotope/Mass Spectrometry Methods. R. R. Wolfe, editor. Alan R. Liss, Inc., New York. 55-65.

24. Hostler, K. Y., and B. R. Landau. 1967. Estimation of the pentose cycle contribution to glucose metabolism in tissue in vivo. Biochemistry. 6:1521-1526.

25. Rossetti, L., and A. Giaccari. 1990. Relative contribution of glycogen synthesis and glycolysis to insulin-mediated glucose uptake: a dose-response euglycemic clamp study in normal and diabetic rats. J. Clin. Invest. 85:1785-1792.

26. Hales, C. N., and P. J. Randle. 1963. Immunoassay of insulin with insulin antibody precipitate. Biochem. J. 88:137-146.

27. Miles, J. R., J. Glasscock, J. Aikens, J. Gerich, and M. Haymond. 1983. A microfluorimetric method for the determination of free fatty acids in plasma. $J$. Lipid Res. 24:96-99.

28. Hohorst, H.-J. 1965. L-(+)-lactate: determination with lactic dehydrogenase and DPN. In Methods of Enzymatic Analysis. H.-V. Bergmeyer, editor Academic Press, Inc., New York. 266-270.

29. Somogyi, M. 1939. A method for preparation of blood filtrates for the determination of sugar. J. Biol. Chem. 86:655-659.

30. Mahon, M. M., W. F. Schwenk, M. W. Haymond, and R. A. Rizza. 1989. Underestimation of glucose turnover measured with $\left[6-{ }^{3} \mathrm{H}\right]-$ and $\left[6,6-{ }^{2} \mathrm{H}_{2}\right]-$ but not $\left[6-{ }^{14} \mathrm{C}\right]$ glucose during hyperinsulinemia in humans. Diabetes. 38:97-107.

31. Scheinberg, P., and E. A. Stead, Jr. 1949. Cerebral blood flow in male subjects as measured by the nitrous oxide technique: normal values for blood flow, oxygen utilization, glucose utilization, and peripheral resistance with observation on the effect of tilting and anxiety. J. Clin. Invest. 28:1163-1171.

32. Rowe, G. G., G. M. Maxwell, C. A. Castillo, D. J. Freeman, and C. W. Crumptom. 1959. A study in man of cerebral blood flow and cerebral glucose, lactate and pyruvate metabolism before and after eating. J. Clin. Invest. 38:21542158.

33. Young, A. A., C. Bogardus, D. Wolfe-Lopez, and D. M. Mott. 1988. Muscle glycogen synthesis and disposition of infused glucose in humans with reduced rates of insulin-mediated carbohydrate storage. Diabetes. 37:303-308.

34. Shulman, G. I., D. L. Rothman, T. Jue, P. Stein, R. A., De Fronzo, and R. G. Shulman. 1990. Quantitation of muscle glycogen synthesis in normal subjects and subjects with non-insulin-dependent diabetes by ${ }^{13} \mathrm{C}$-nuclear magnetic resonance spectroscopy. N. Engl. J. Med. 322:223-228.

35. Bogardus, C., L. Lillioja, K. Stone, and D. Mott. 1984. Correlation between muscle glycogen synthase activity and in vivo insulin action in man. $J$. Clin. Invest. 73:1186-1190.
36. Mandarino, L., Z. Mader, O. G. Kolterman, J. M. Bell, and J. M. Olefsky. 1986. Adipocyte glycogen synthase and pyruvate dehydrogenase in obese and type II diabetic subjects. Am. J. Physiol. 251:E489-E496.

37. Kelley, D. E., and L. J. Mandarino. 1990. Hyperglycemia normalizes insulin-stimulated skeletal muscle glucose oxidation and storage in non-insulindependent diabetes mellitus. J. Clin. Invest. 86:1999-2007.

38. Garvey, W. T., T. P. Huecksteadt, S. Mattaei, and J. M. Olefsky. 1988. Role of glucose transporters in the cellular insulin resistance of type II non-insulin-dependent diabetes mellitus. J. Clin. Invest. 81:1528-1536.

39. Dohm, G. L., E. B. Tapscott, W. J. Pories, D. J. Dabbs, E. G. Flickinger, D. Meelheim, T. Fushiki, S. M. Atkinson, C. W. Elton, and J. F. Caro. 1988. An in vitro human muscle preparation suitable for metabolic studies: decreased insulin stimulation of glucose transport in muscle from morbidly obese and diabetic subjects. J. Clin. Invest. 82:486-494.

40. Bonadonna, R. C., S. Del Prato, C. Cobelli, M. P. Saccomanni, D. Bier, E. Ferrannini, and R. A. De Fronzo. 1990. Glucose transport in skeletal muscle is insulin-resistant in type 2 diabetes. Diabetologia. 33(Suppl.1):A23.

41. De Fronzo, R. A., R. Gunnarsson, O. Björkman, M. Olsson, and J. Wharen. 1985. Effects of insulin on peripheral and splanchnic glucose metabolism in noninsulin-dependent (type II) diabetes mellitus. J. Clin. Invest. 76:149155

42. Laakso, M., S. V. Edelman, G. Brechtel, and A. D. Baron. 1990. Decreased effect of insulin to stimulate skeletal muscle blood flow in obese man: a novel mechanism for insulin resistance. J. Clin. Invest. 85:1844-1852.

43. De Fronzo, R. A., E. Ferrannini, R. Hendler, P. Felig, and J. Wahren. 1983. Regulation of splanchnic and peripheral glucose uptake by insulin and hyperglycemia in man. Diabetes. 32:35-45.

44. Grill, V. 1990. A comparison of brain glucose metabolism in diabetes as measured by positron emission tomography or by arteriovenous techniques. Ann. Med. 22:171-176.

45. Kelley, D. E., J. P. Reilly, T. Veneman, and L. J. Mandarino. 1990. Effects of insulin on skeletal muscle glucose storage, oxidation, and glycolysis. Am. J. Physiol. 258:E923-929.

46. Groop, L. C., R. C. Bonadonna, M. Shank, A. S. Petrides, and R. A. De Fronzo. 1991. Role of free fatty acids and insulin in determining free fatty acid and lipid oxidation in man. J. Clin. Invest. 87:83-89.

47. Randle, J. P., P. B. Garland, and E. A. Newsholme. 1963. The glucose fatty acid cycle: its role in insulin sensitivity and the metabolic disturbances of diabetes mellitus. Lancet. $i$ : 785-789.

48. Thoburn, A. W., B. Gumbiner, F. Bulacan, P. Wallace, and R. R. Henry. 1990. Intracellular glucose oxidation and glycogen synthesis activity are reduced in non-insulin-dependent (type II) diabetes independent of impaired glucose uptake. J. Clin. Invest. 85:522-529.

49. Butler, P. C., E. J. Kryshak, M. Marsh, and R. A. Rizza. 1990. Effect of insulin on oxidation of intracellularly derived glucose in patients. with NIDDM evidence for primary defect in glucose transport and/or phosphorilation but not oxidation. Diabetes. 39:1373-1380.

50. De Fronzo, R. A., and E. Ferrannini. 1982. Hepatic and peripheral insulin resistance: a common feature in non-insulin dependent and insulin dependent diabetes. Diabetologia. 23:313-319.

51. Ferrannini, E., D. C. Simonson, L. D. Katz, G. A. Reichard, S. Bevilacqua, E. J. Barrett, M. Olsson, and R. A. De Fronzo. 1988. The disposal of an oral glucose load in patients with non-insulin-dependent diabetes. Metab. Clin. Exp. 37:79-85.

52. Firth, R. G., P. M. Bell, H. M. Marsh, I. Hansen, and R. A. Rizza. 1986. Postprandial hyperglycemia in patients with noninsulin-dependent diabetes mellitus. J. Clin. Invest. 77:1525-1532.

53. Golay, A., J. P. Felber, R. A. De Fronzo, and E. Ferrannini. 1988. Metabolic basis of obesity and non-insulin dependent diabetes mellitus. Diabetes $\mathrm{Me}$ tab. Rev. 4:727-747.

54. Bogardus, C., A. Lillioja, K. Stone, and D. Mott. 1984. Correlation of muscle glycogen synthase activity and in vivo insulin action in man. J. Clin. Invest. 73:1185-1190. 